\title{
Exploration and Research on Discussion Group Teaching Mode Based on Training Innovative Ability in Algorithm Design and Analysis Course
}

\author{
Yintong Wang ${ }^{1, *}$, Wenjie Xiao ${ }^{1}$, Yanqing Wang ${ }^{1}$ \\ ${ }^{1}$ School of Information Engineering, Nanjing Xiaozhuang University, Nanjing, Jiangsu 211171, China \\ *Corresponding author. Email: heaven_456369@126.com
}

\begin{abstract}
The course of algorithm design and analysis can make students understand the theory of algorithm complexity, master the calculation of time complexity and space complexity, and solve common practical problems in the process of computer application. However, the teaching content of this course is relatively difficult, and the level of abstraction of many knowledge is high. It is insufficient to achieve the teaching goals with the traditional teaching and curriculum evaluation. This paper proposes a discussion teaching mode based on training innovative ability in algorithm design and analysis course, which emphasizes the student's subject position in learning and the teacher's dominant position in teaching. It takes group activities as the basic form and promotes research-based instructional strategies and classroom techniques, and then promotes the development of students' communication ability and innovative thinking ability.
\end{abstract}

Keywords: Algorithmic design and analysis, Group discussion, Teaching mode

\section{INTRODUCTION}

Algorithm design and analysis, as one of the core courses of computer science, takes into account both theoretical and practical characteristics. As a compulsory basic course for undergraduates and graduate students majoring in computer science, the course is extremely important for students to understand and master the basic methods of algorithm design and to correctly analyse the time complexity and space complexity of algorithms. It is also of vital importance to cultivate students' systematic programming ideas and exercise students' logical thing ability $[1,2]$. Through investigation, it is not difficult to find that the current teaching effect of algorithm design and analysis course is not that ideal, the traditional teaching methods have many adverse effects on students' enthusiasm and enthusiasm for learning this course.

The main reasons for this problem can be summarized as the following three points: (1) The knowledge points of the course are many and complex, and it is not easy to understand, only traditional algorithm design method is explained, and it is difficult to guide and expound the algorithms in the fields of artificial intelligence and deep learning from a high standard. (2) The teaching ideas are relatively backward, and still stay in the teaching mode oriented to imparting knowledge. Some teachers may copy and follow the textbooks, and lack interaction with and guidance to the students in the teaching process so that it is not only difficult for students to find the beauty of the thinking contained in algorithm course, but also difficult for students to have a strong interest in the content of the course. (3) The learning of this course requires knowledge of programming, data structure, logical mathematics, etc., and the inconsistent level of basic knowledge reserve of students restricts the formulation of teaching content and teaching schedule. In the long run, students gradually lost their interest and enthusiasm in learning algorithm design and analysis courses, and also lost the ability of the course to learn independently [3]. And then, the consequence is that it severely restricts the development of students' innovative ability and practical ability.

In addition, under the background of new engineering construction, computer majors are facing new opportunities and challenges. It is an urgent matter and a long-term strategy to update the teaching concept in time and cultivate creative talents with core competence, the creative talents must have strong ability of independent learning, information acquisition, observation and analysis, communication and cooperation [4-6]. Therefore, teachers should take students as the main subject in teaching this course, and while teaching basic algorithms, they should pay more attention to the cultivation of students' independent thinking and the ability to solve problems in unity and cooperation.

Regarding the above problems, this paper introduces discussion group teaching mode based on training innovative ability in algorithm design and analysis course, where the group discussion teaching mode is to organize students to carry out group discussions by allocating certain class hours in a planned way. It is particularly important that the students' dominant position is emphasized and the teacher's dominant position is affirmed in the whole teaching process. Through group discussion teaching, students can improve their ability to discover, analyse and solve problems in this course, and can also improve students' comprehensive ability of unity and 
cooperation, mutual promotion and communication, so that students can change from passive learning to active learning to better cultivate students' creative thinking.

\section{PROBLEMS IN THE TEACHING OF ALGORITHM DESIGN AND ANALYSIS COURSE}

Algorithm design and analysis course has a high degree of abstraction and is flexible in application; meanwhile, it has a good inspiration and guidance for learning of the remained professional courses [7]. Like other courses, classroom teaching activities are not only a process for teachers to impart knowledge, but also a process for cultivating students to use algorithmic ideas to solve practical problems. Reasonable and effective organization of classroom teaching activities has a very important impact on the improvement of students' learning initiative and the ability of students to use knowledge flexibly. At present, most of the undergraduate colleges still use the traditional teacher-centered teaching model for the teaching of algorithm design and analysis courses. This teaching model is not compatible with the initiative of students' learning subjects, the current level of information technology development and the evaluation mechanism of instant learning effects. The problems faced by the traditional teaching mode of algorithm design and analysis course can be summarized as follows:

(1) The teaching mode is monotonous, and the students' enthusiasm for learning is insufficient. Many colleges still use the traditional teaching mode for algorithm design and analysis course teaching, and the multimedia teaching equipment only gives relevant theoretical knowledge in the form of demonstration. This kind of "cramming" teaching method often leads students to lack active thinking in class, to cause the level of participation in teaching is low, and then to exhausting students' learning enthusiasm.

(2) Focus on the basic algorithm strategy, the practical problem solving is missing. The content of algorithm design and analysis courses is relatively scattered and independent. There is no close connection between different types of problem design methods. It is difficult for students to fully grasp the characteristics and interrelationships of each method. The basic idea of algorithm design for classic problems or cases is often the only way to explain each method, lacking training in solving practical problems. The result of this is that students can complete the algorithmic solution of book problems. When faced with new practical problems, most students will be in a helpless situation and lack the ability to flexibly use algorithmic ideas to solve problems.

(3) There is a gap between the course evaluation mechanism and student performance and ability. The course evaluation mechanism of algorithm design and analysis usually includes the final exam results and the usual assessment results, which are reflected in class attendance rate, homework assignments, and experimental results. Due to the lack of a reasonable and effective curriculum evaluation mechanism, there is a more common situation, that is, students have obtained better course evaluation results, but his/her practical ability and practical problem-solving ability still insufficient.

\section{DISCUSSION GROUP TEACHING MODE BASED ON TRAINING INNOVATIVE ABILITY IN ALGORITHM DESIGN AND ANALYSIS COURSE}

\subsection{Design of Discussions Group teaching mode}

Aiming at the problem of students' lack of initiative in the process of algorithm design and analysis teaching, combined with years of front-line teaching experience, this paper proposes that the group discussion teaching mode is the form of group discussion of students for classroom teaching interaction, which helps to improve Students' enthusiasm for learning [3]. This mode can also make the students' pre-preparation and post-class extension work truly implement, prompting most students to actively think, discuss and answer the teacher's discussion questions, and transform students from a negative observer to an active participant.

The group discussion teaching mode introduced into algorithm design and analysis class course is mainly divided into three stages. First, students grouping. The task should be completed by themselves; the number of each group is controlled at 4-6; teacher should emphasize that the record of each group discussion will be directly related to the usual performance evaluation of the students in the group, and review each group and make necessary adjustments, and publicize the grouping list to enhance students' group awareness. Second, group discussion in class. On the basis of the students' pre-class preparation work, the teacher will first explain the algorithm strategy concepts and involved cases (problem discovery, problem analysis, algorithm design, algorithm implementation and analysis). Answer the questions involved in students' Preview work; discussion topics and requirements are displayed in the form of blackboards or projections, and students are urged to complete the discussion within the corresponding requirements. During the discussion, teachers should supervise and motivate students to think and discuss issues more actively, and correct the discussion of individual groups in a timely manner. After the group discussion is completed, the teacher can designate 1-3 groups according to the pre-plan, and each group can recommend a student to explain, and other groups of students give supplementary explanations. The teacher records the discussion and problem solving of each group. Finally, discuss the topic summary. After the discussion, the teacher will discuss the difficulties involved in the question and give a collective explanation, and briefly summarize the group's answer to the question. 


\subsection{Key Points of Discussions Group Teaching Mode}

The teaching content of the group discussion should be carefully screened and designed, which can greatly transfer the students' interest and enthusiasm in the course of algorithm design and analysis. Compared with the traditional teaching model, which focuses on the one-way dissemination of knowledge, the group discussion teaching model focuses more on students' communication and innovative thinking, which is based on the students' deep understanding of the discussion issues. Therefore, the teaching implementation points of group discussion can be summarized into the following four points:

(1) Based on the multidisciplinary intersection of computers. The content of algorithm design and analysis involves computer science, mathematics, statistics and graph theory, has the characteristics of multi-disciplinary cross-integration, wide coverage of basic knowledge, and strong theoretical. The teaching purpose of the course is to guide students to master the basic processes and ideas of using computer to analyse, design and solve a problem, and cultivate their computational thinking ability by seeking for a solution to a problem.

(2) Adhere to the problem-oriented practicality. Algorithm design and analysis is a highly practical course. Algorithm ideas come from mathematics and logic, and are finally realized through computer programming languages. Through the course study, students consolidate the relevant theories and basic knowledge of algorithm design and analysis, understand the algorithm solution ideas, and master the core content of algorithm research, in order to further achieve the qualitative improvement of computer-related curriculum skills such as programming, data structure, and software engineering. In practical work, the problems encountered by practitioners are often oriented to a brand-new environment and platform, and it is difficult to find a complete matching engineering solution from the textbook, which makes the existing algorithm development and programming implementation face great challenges. In response to these challenges, teachers should introduce practical problems into the course teaching to cultivate students' awareness of solving practical problems and innovative thinking.

(3) Keep up with the frontier of technological development. Although the algorithm design and analysis courses are mainly based on the teaching of algorithm basic knowledge and classic case solving ideas, in order to better adapt to the development of computer technology and reflect the prospective of university teaching, we need to take into account the frontier of technology development in the computer field. Usually, the basic algorithms have been shown in the form of classic cases in the textbook, and the frontier technology that are of great help in solving practical problems need to be understood and mastered. In the group discussion teaching mode, the topics for discussion of frontier technology should be determined in accordance with the development trend of computer science and the future employment needs of students, taking into account the latest research topics of our teachers, and appropriately combining new technologies such as artificial neural networks.

(4) Promote continuity of learning after class. After the group discussion, the students have a deeper understanding of the discussion issues, and should continue to pay attention to and strengthen the follow-up exploration of the discussion issues to make the classroom teaching sustainable. In the subsequent stages of the group discussion, students are motivated to learn actively by designing a more comprehensive course experiment. Especially in the later stages of the course, the content of the experiment is difficult, and the knowledge required to solve the problem is often insufficient to be taught by the teacher in the classroom. Students also need to consult a large number of extracurricular literatures to enrich their knowledge.

\subsection{Implementation of Group Discussions Teaching Mode}

In the teaching activities, the leading role of teachers has always been affirmed, and they can complete the corresponding course teaching goals with reasonable and effective teaching methods and management methods. Compared with the traditional teaching mode, the group discussion teaching mode emphasizes the student's subject position in learning and the teacher's dominant position in teaching. From the above mode design and key points of group discussion teaching, we known that the discussion group teaching mode based on training innovative ability in algorithm design and analysis course originating from the traditional teaching model, and through question discussion to improve the student's subjective initiative and expand the student's knowledge transcending the traditional teaching mode. Therefore, the roles of teachers and students should also have certain literacy requirements in the process of implementing the group discussion teaching mode. As shown in Figure 1, the implementation of group discussion teaching consists of three stages before, in and after the class. The specific contents are as follows:

(1) Pre-class preparation stage. Teacher roles designs discussion topics and plans discussion process. The discussion topic is the core and effective carrier of group discussion. It should not only be based on the content of the textbook, highlight the key points, and complete the teaching objectives, but also ensure that the discussion topic is novel so that the students have a strong interest in the discussion, which can broaden the students' innovative thinking, and then improve students' independent thinking ability. In the design of the problem process, teachers should have the value of discussion, the difficulty should 


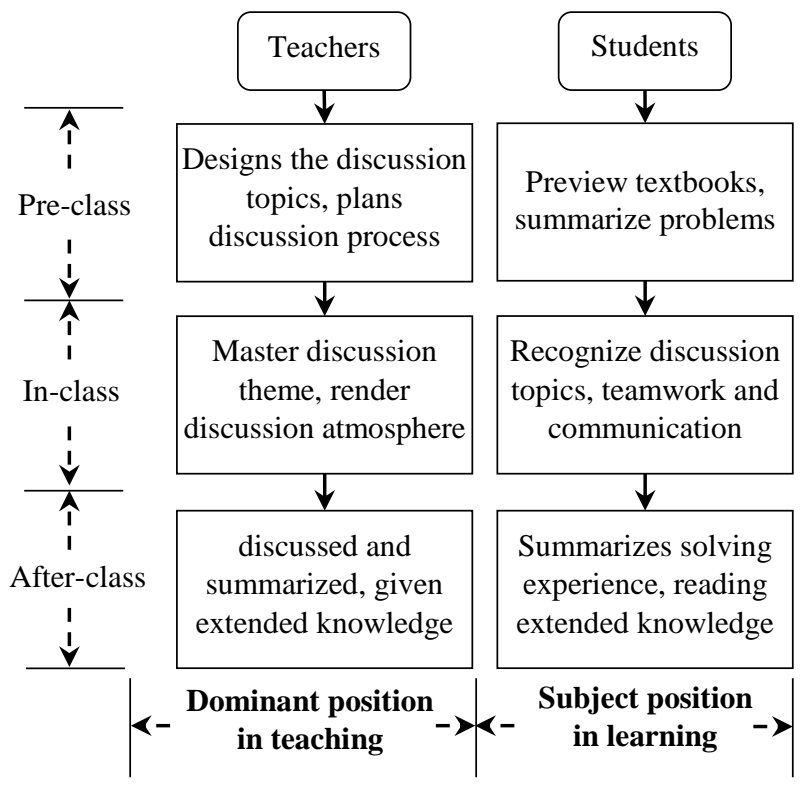

Figure 1. Teacher roles and student roles in discussion group teaching

be appropriate and the amount of questions should be moderate, but also pay attention to grasp the timing of the question, the application of the wording, and set the question flexibly according to the student's situation. Student roles preview textbooks and summarize problems. Students should preliminarily complete the acceptance and understanding of knowledge through selfstudy textbooks and related materials. When face with encounter problems, they can carry out pre-class group discussions. Record unresolved problems so that submit questions in the classroom and give them to teachers to explain or organize discussions.

(2) In-class implementation stage. Teacher roles should be able to master discussion theme and render discussion atmosphere. They have multiple abilities of abundant knowledge reserves, adaptable, capture and create discussion opportunities. During the discussion, when the student's discussion deviates from the theme, the teacher should guide the student's discussion to the discussion theme, so that the classroom discussion will develop toward the set goal. When the student group encounters difficult problems or falls into the " prove me to be myself " dilemma, the teacher must make appropriate prompts or instructions to help the student overcome the discussion barrier. Let each student actively participate in the discussion to ensure that each student's ability to solve practical problems can be exercised and improved. Student roles recognize discussion topics, teamwork and communication. Carefully review the topic, think positively, read the textbooks carefully, collect materials, organize, analyse, summarize the materials, carefully prepare the opinions and write the outline of the speech. Actively speak in the classroom, express their own views or ideas, fully experience the joy of success, and share them with your classmates. Learn to comprehensively and objectively comment on the different views of others and accept the different opinions of others, so as to communicate, learn and enlighten each other, and finally achieve the common improvement of all students.

(3) After-class extension stage. Teacher roles should be discussed and summarized, and given extended knowledge points. After each discussion question, the teacher should make an objective, accurate and comprehensive evaluation of the discussion, certainly positive aspects, and point out the shortcomings. For students who have different opinions, teachers must have a clear point of view, concise and key points, and clarify the vague understanding in order to improve the level of knowledge and ability of the students, so that there will be a qualitative change in understanding. Classroom knowledge points should play a good role in bringing points to face. Teachers arrange extended knowledge points as homework for the knowledge learned in the classroom, and urge students to complete the homework to consolidate the knowledge and broaden the knowledge. Student roles summarizes problem solving experience, reading extended knowledge points. No one ever stop learning so our should be keep learning from in-class to after-class. Students do not have a firm grasp of the classroom or need to re-learn the content can review after class, the purpose of which is to deepen the understanding and mastery of the learned knowledge. Another, students earnestly complete the extended knowledge points arranged by teachers to promote the further improvement of the knowledge and skills they have learned.

\subsection{Course Evaluation}

Curriculum evaluation is an indispensable part in the teaching process, and it is also one of the important ways to measure the learning level of students and assess the teaching quality of teachers. A good curriculum evaluation mechanism can better promote and urge students to learn and master what they have learned, and improve students' ability to analyse and solve problems. At present, the performance evaluation of algorithm design and analysis course is mainly based on the final exams and usually supplemented by homework. The proportion of these two parts in the final scores is $70 \%$ and $30 \%$, respectively. However, in the discussion group teaching mode based on training innovative ability in algorithm design and analysis course, group discussion occupies a very important proportion, which is also conducive to teachers in a timely manner to grasp the student's learning status, in order to facilitate further implementation process assessment. In addition, the process assessment can effectively prevent students from making surprise preparations at the end of the semester in the form of exams, which also improves students' enthusiasm for learning at ordinary times. Therefore, the curriculum design of the group discussion teaching mode needs to strengthen the process assessment, based on the discussion and participation records of each group, to assess their usual performance, and improve the proportion of this part score in the final score. 


\section{CONCLUSION}

The algorithm design and analysis course itself is highly abstract and difficult. It not only focuses on theoretical analysis, but also on practical operation ability, and then puts forward high requirements for students. This article aims at the problems in the existing classroom teaching, explores the discussion group teaching mode based on training innovative ability in algorithm design and analysis course from teaching mode design, teaching implementation key points and teacher and student roles' quality. It aims to improve students' enthusiasm for selflearning, classroom participation, problem-solving skills and teamwork awareness, and can provide students with a broad and solid foundation of computer algorithm knowledge for future research and development of computer-related applications.

\section{ACKNOWLEDGMENT}

This work was supported by Jiangsu Government Scholarship for Overseas Studies, and Nanjing Xiaozhuang University Classroom Teaching Model Reform Project.

\section{REFERENCES}

[1] J.F. Li, Y. Tang, Y.M. Fu, et al., Teaching Reform of Algorithm Design and Analysis Course Based on "Project Oriented + Autonomous Learning + Practical Training", 3rd International Conference on Education, E-learning and Management Technology, 2018, pp. 312-315. DOI: https://doi.org/10.2991/iceemt-18.2018.60

[2] X.F. Wang, X. Xu, Research on Teaching of Computational Thinking Oriented Algorithm Design Course, 4th International Conference on Contemporary Education, Social Sciences and Humanities, 2019, pp. 346348. DOI: https://doi.org/10.2991/iccessh-19.2019.79

[3] Z.H. Wu, The Introduction of Group Discussion into Classroom Questioning in College English Teaching, Oversea English, 2015, pp. 48-50.

[4] B.D. You, L. Wang, J.J. Zhao, Reflection and Discussion on the Teaching Concept of "Theory of Machines and Mechanisms" Under the Situation of Emerging Engineering, 2019 International Conference on Modern Educational Technology, 2019, pp. 1-5. DOI: https://doi.org/10.1145/3341042.3341043

[5] Y. Yang, D.K. Yu, Theme Division and Team Activities Interactive Teaching Method for Software Engineering, Journal of Software, 2019, pp. 340-349. DOI: https://doi.org/10.17706/jsw.14.7.340-349

[6] G.C. Yin, Exploration and Research on Teaching Mode for the Basic Courses of College Computer under the New
Engineering Background of Colleges and Universities. Frontiers in Educational Research, 2019, pp. 94-98. DOI: https://doi.org/10.25236/FER.033013

[7] X.F. Zhang, L.H. Song, P. Lei, Discussion of Deliberative Teaching in Algorithm Analysis and Design, China Modern Educational Equipment, 2018, pp. 38-40. DOI: https://doi.org/10.13492/j.cnki.cmee.2018.17.015 